\title{
A educação ambiental diante da problemática socioambiental na ideologia capitalista
}

The Environmental Education in the face of Problematic Socio-environmental In the Capitalist Ideology

\section{Zilda Maria de Oliveira Lana'}

'Mestranda- Programa de Pós- Graduação em Educação da Pontifícia Universidade Católica de Minas Gerais, Belo Horizonte - MG, Brasil

\begin{abstract}
Resumo
Este artigo busca refletir sobre as mudanças ocorridas, na sociedade, em virtude do modelo de desenvolvimento capitalista. Problematiza a função de reprodução ideológica das instituições escolares e o papel da Educação Ambiental conservacionista difundida nas escolas, apresentando a concepção crítica como alternativa para uma transformação social na qual seja instaurada uma sociedade mais equânime. A Educação Ambiental Crítica denuncia a agressividade e a raiz da crise socioambiental, e prioriza a formação e a emancipação dos sujeitos, em movimento contrário à reprodução e à formação alienada associada à Educação Ambiental Conservacionista.
\end{abstract}

Palavras-chaves: Problemática socioambiental. Ideologia Capitalista. Educação Ambiental.

\begin{abstract}
This article seeks to reflect about the changes in society due to the model of capitalist development. It reflects on the issues regarding the ideological reproduction of the scholar institutions and the role of conservationist Environmental Education among the schools showing a critical conception as an alternative for social transformation in which an equitable society can be formed. Critical Environmental Education shows the aggression and the roots of the socio-environmental crisis, and gives priority to the formation and emancipation of the subjects in an opposite movement to the reproduction and alienated formation associated to the Conservationist Environmental Education.
\end{abstract}

Keywords: Environmental Issues. Capitalist Ideology. Environmental Education. 


\section{INTRODUÇÃO}

A implantação e a expansão do modelo de desenvolvimento capitalista provocaram mudanças, na sociedade, que amplificaram os problemas socioambientais, de forma a comprometer a sustentabilidade ambiental. A reprodução da ideologia do capitalismo, que impregna as práticas escolares, torna esses problemas comuns, naturalizando-os, como se fossem inerentes à sociedade humana. Nesse cenário, a educação ambiental crítica torna-se importante meio para denunciar a intencionalidade dessa reprodução e contribuir para a construção de uma sociedade com menos destruições socioambientais.

Para o desenvolvimento do texto, inicialmente busca-se tecer reflexões acerca da problemática socioambiental associada ao modelo de desenvolvimento capitalista. Expandido aos fins da Idade Média, esse modelo instaura uma racionalidade econômica apoiada em pressupostos de exploração social e ambiental que geram desigualdades, violência e destruições socioambientais. Em seguida, visitam-se conceitos como materialismo histórico, ideologia e aparelhos ideológicos para sustentar a discussão a respeito do papel das escolas na reprodução capitalista e da manutenção da opressão na sociedade, tolhendo as tentativas de desmascaramento da racionalidade capitalista. Por fim, aborda-se sobre a potencialidade da Educação Ambiental Crítica como possibilidade de emancipação política, social e ambiental dos cidadãos, ressaltando-se a necessária distinção entre a concepção crítica e a concepção conservacionista da Educação Ambiental.

\section{METODOLOGIA}

O presente trabalho, de caráter qualitativo (BODGAN; BIKLEN, 1994), utilizou como técnica, ou recurso, para sua construção a pesquisa bibliográfica (MARCONI; LAKATOS, 2002). Pesquisa essa que permite o exame de determinado assunto através de referenciais em fontes secundárias.

Para a construção das reflexões tecidas nesse artigo, recorreu-se a textos diversos, tais como dissertações, artigos de periódicos e livros, denominados de fontes secundárias, que contemplavam a temática analisada, buscando relacionar e reunir informações acerca de temas como educação ambiental, ideologia capitalista e problemas socioambientais que pudessem fundamentar, de forma sólida, os conhecimentos aqui construídos.

\section{RESULTADOS E DISCUSSÃO}

\subsection{Sociedade capitalista e a problemática socioambiental}

O final da Idade Média representou grandes mudanças nas relações sociais, políticas e econômicas. O paradigma teológico deu lugar à razão, ressaltando o caráter científico e racional que passa a orientar a sociedade. As emergências das Revoluções Burguesa e Industrial instauram e afirmam o novo modo de produzir, pensar e agir. A vida na sociedade passa a apresentar um caráter mais utilitarista, onde a racionalidade da produção econômica tende a orientar os caminhos de toda a sociedade.

O pensamento suportado por Karl Marx permite questionar o modelo de civilização capitalista em voga, inaugurado no período pós Idade Média, expondo as contradições nele existentes (MARX; ENGELS, 2007). Dentre elas, pode-se citar: as contradições de classe e de propriedade; e a incompatibilidade entre o paradigma de desenvolvimento capitalista e a sustentabilidade ambiental. Marx (1996, p. 132) alerta que "[...] a produção capitalista acumula, por um lado, a força motriz histórica da sociedade, mas perturba, por outro lado, o metabolismo entre homem e terra [...]".

A natureza, em seu sentido ecológico, inalterada, sob a ótica do capitalismo, é vista como ambiente ainda improdutivo e que, para expressar a civilidade do homem, precisa ser explorado e direcionado a oferecer o mesmo subsídio para o avanço tecnológico e científico. Avanços esses que subsidiam a corrida pela implantação de tecnologias que permitem, de forma cada vez mais intensa, a modificação do ambiente natural, a retirada de matéria prima e a transformação da mesma em bens de consumo cada vez mais cobiçados pelos homens. Homens que passam a expressar, em seus hábitos de consumo e relação com o meio que o cerca, não mais uma relação de necessidade, mas de exploração para a ostentação de produtos que passam a estar associados ao seu status social. O mercado de consumo não aparece mais para suprir as necessidades humanas, 
mas sim para criar tais necessidades, como meio de se manter na dominação política, econômica e social, implantando, nas relações sociais, a monetarização do ser humano. "[...] a vida digna perde seus conteúdos sociais e éticos para tornar-se mercadoria." (TREIN, 2007, p. 118).

Nesse mesmo sentido, as ordens social e ambiental são dominadas por uma intencionalidade de mercado, visando lucro indiscriminado, que, por consequência, gera grandes prejuízos ambientais e sociais.

Associada à exploração do meio ambiente ecológico, intensifica-se, também, a exploração do homem. Como afirma Pedrosa (2007, p. 91), “[...] a relação de dominação que o homem estabelece com a natureza caracteriza o protótipo da relação, também de dominação, que os homens estabelecem entre si." Aqueles que detêm o poder político e econômico passam a comandar e direcionar todo o modo de produção, e a outra parcela da sociedade passa a vender sua força de trabalho, conhecendo a exploração, as desigualdades e as mazelas nas quais foi inserida.

[...] a transformação capitalista do processo de produção aparece, ao mesmo tempo, como martirológio dos produtores, o meio de trabalho como um meio de subjugação, exploração e pauperização do trabalhador, a combinação social dos processos de trabalho como opressão organizada de sua vitalidade, liberdade e autonomia individuais. [...] E cada progresso da agricultura capitalista não é só um progresso na arte de saquear o trabalhador, mas ao mesmo tempo na arte de saquear o solo, pois cada progresso no aumento da fertilidade por certo período é simultaneamente um progresso na ruína das fontes permanentes dessa fertilidade. [...] a produção capitalista só desenvolve a técnica e a combinação do processo de produção social ao minar simultaneamente as fontes de toda a riqueza: a terra e o trabalhador. (MARX, 1996, p. 133)

O modelo de desenvolvimento que tem se expandido pelo globo tende a imitar os padrões de produção e de consumo dos países industrializados. Aos países ditos subdesenvolvidos, o modelo capitalista tem vendido sua lógica de exploração, convencendo-os de que devem buscar pela industrialização e comercialização mundial, pois seria esse o caminho natural de desenvolvimento e progresso de uma nação. No entanto, trata-se de um estilo que não apenas tem gerado desigualdade e iniquidade, provocando o surgimento, nos países desenvolvidos modernos, de encraves que beneficiam uma elite feita à imagem e à semelhança de um mundo desenvolvido, mas que também tem destruído o meio ambiente e seus recursos - base natural de todo o desenvolvimento e suporte vital dos processos biológicos e culturais. (GONZALEZ; KATRA, 2009, p.52).

Pensar os problemas ambientais isolados e desconexos das outras esferas da sociedade é uma ingenuidade. O paradigma civilizatório pelo qual passa o cenário mundial, além de aspectos ecológicos, se apoia em problemas políticos e sociais que contribuem para uma crise chamada socioambiental, uma vez que, associado à problemática de destruição do meio ambiente natural, também se encontra problemas como má distribuição de renda, miséria, exclusão social, violência e opressão.

A humanidade se encontra diante de uma crise que é geral, atinge a todos e engloba aspectos culturais, econômicos, políticos, e históricos (GONZALEZ; KATRA, 2009). Trata-se de uma crise que, mesmo de formas desiguais, atinge a todos, independentemente do continente, do país ou da sociedade em que se vive. Trata-se de uma crise global, planetária. Alguns sofrem com a falta de água potável e de saneamento básico, com a falta de cuidados médicos, e com o consumo de drogas. Outros sofrem com o consumo excessivo de alimentos industrializados, com doenças associadas à ingestão de gordura e conservantes (LIMA, 2002). "O atual modelo de desenvolvimento produz exclusão social e miséria, por um lado, e consumismo, opulência e desperdício, por outro" (DIAS, 2004, p.11).

Cabe pontuar que, apesar de ser uma crise que afeta a todos, não se pode negar a maior violência com que essa atinge os oprimidos, os quais se nega o conhecimento, a criticidade, a participação, o direito de se reconhecerem como cidadãos. Aos oprimidos são socializadas as mazelas, e aos opressores são privatizadas as beneficies de seus "lucros" produzidos e arrancados pela exploração desumana da sociedade.

\subsection{Ideologia capitalista e educação ambiental (EA) na escola}

Karl Marx apresenta uma visão sobre a sociedade e sua história que se distancia da neutralidade do pensamento positivista. Considera que a história da sociedade é uma história de luta de classes 
antagônicas e interdependentes (materialismo dialético), e, ainda, que as relações existentes nas diversas esferas da sociedade, como família, cultura e educação, seriam determinadas por fatores econômicos (infraestrutura e superestrutura). Desse modo, a classe dominante realiza esforços no sentido de infiltrar e impregnar a vida da classe oprimida de valores e interesses necessários à manutenção do status quo de dominação estabelecida.

Tomando como ponto de partida o materialismo histórico de Marx e os conceitos de infraestrutura e superestrutura, assume-se que a educação sempre esteve atrelada e dependente de outras estruturas sociais, em especial ao modelo de desenvolvimento econômico e político, onde o modo de produção da sociedade condiciona todas as demais formações. Daí se avista que a educação e a escola se apresentam como um prolongamento da estrutura de poder da sociedade, poder econômico, em especial, que determina os rumos das demais instâncias da sociedade. Nessa perspectiva, a educação tem sido utilizada como instrumento de amplificação de uma ordem social instaurada, que beneficia àqueles que ocupam posições de poder, direcionando a formação dos cidadãos para atingir os anseios da classe dominante.

Nos dizeres de Gadotti (2010), a educação nunca esteve separada das questões do poder, e aqueles que defendem que a educação é neutra, na verdade, estão tentando ocultar o projeto político que há por trás da mesma, reduzindo sua capacidade de mobilização à reprodução de modelos prontos estabelecidos que interessem a poucos.

O prolongamento de estrutura de poder econômico sobre a sociedade rodeia a formação dos homens, que, acostumados com o sistema de ideias e representações do grupo social dominante, internalizam o padrão necessário à manutenção do desenvolvimento capitalista. Nesse padrão, os homens são treinados e acostumados com a estrutura do capitalismo e a veem como natural. O pensamento marxista:

[...] ao desvendar o modo de produção capitalista, sua estrutura interna, as contradições que engendra enquanto processo social, seus limites materiais, aponta também os mecanismos de ocultamento dessa realidade, elaborados pela ideologia dominante." (TREIN, 2007, p. 122)

O processo de internalização, no qual os homens se acostumam e passam a reproduzir uma lógica de determinado grupo social, tida como natural, chama-se de ideologia. Nesse processo, os referenciais simbólicos difundidos pela classe dominante, que condicionam a visão de mundo alheia, representam interesses específicos que são difundidos de modo pacífico. Os sujeitos são convencidos a

[...] orientarem-se por valores que os mantenham acomodados, subservientes, inofensivos, sem perceberem que estão sendo socialmente oprimidos, culturalmente violentados, economicamente explorados, e muitas vezes, ecologicamente afetados, e, portanto, sem desejarem reagir e alterar as injustas relações sociais, por considerar esse estado de coisas absolutamente normal, fora de seu controle. Layrargues (2003, p. 39)

A ideologia é capaz de legitimar a opressão característica do capitalismo, fazendo crer que a exploração humana e da natureza são necessárias ao desenvolvimento econômico-social, afastando a criticidade e promovendo a aceitação pacífica e fácil da lógica opressora, propositadamente distorcida pela classe dominante, a fim de manter seu status de dominação.

Além da ideologia, em Althusser (1980), outro conceito de grande importância é discutido: os aparelhos ideológicos do Estado, que são instituições aparentemente distintas, especializadas e neutras, que, no entanto, expressam os anseios da classe dominante. Servem como meios de transmissão da ideologia capitalista, de forma amena e aparentemente desinteressada.

Dentre os aparelhos ideológicos do Estado (ALTHUSSER, 1980), cita-se o familiar, o jurídico, o político, o cultural e o escolar. Sendo este último representado pelas instituições escolares, foco dessa discussão. As escolas, aparentemente neutras, estão fortemente compromissadas com a manutenção da ideologia capitalista, indicando os papéis sociais a que serão direcionados os indivíduos das diferentes classes sociais, pré-determinando o sucesso ou o fracasso individual e de classe dos seres escolares, direcionando uns como força de trabalho e outros como futuros donos dos meios de produção, tentando perpetuar a relação de exploração estabelecida entre opressores e oprimidos. Nos dizeres de 
Althusser (1980), ao mesmo tempo em que a escola ensina técnicas e conhecimentos, ensina também

[...] as regras dos bons costumes, isto é o comportamento que todo agente da divisão do trabalho deve observar, segundo o lugar que está destinado a ocupar: regras da moral, das consciências cívica e profissional, o que significa exactamente regras de respeito pela divisão social-técnica do trabalho, pelas regras da ordem estabelecida pela dominação de classe. (ALTHUSSER, 1980, p.21)

Apoiada nesses aparelhos ideológicos, tal como na escola, a burguesia consegue intensificar as relações de produção e consumo, estimulando um consumismo exacerbado e cosmopolita, de modo que as pessoas passam a consumir não para suprir suas necessidades pessoais, mas sim as necessidades das fábricas e indústrias que se ampliam, reforçando o sistema capitalista. Como afirmam Marx e Engels (2007), a burguesia revolucionou não somente os instrumentos e as relações de produção, mas também as relações sociais. Expande-se de tal forma a consciência consumidora que o mundo tende a priorizar: um único saber, voltado ao aprimoramento dos meios de produção e tecnologias aplicadas à transformação dos recursos naturais, e uma única cultura, pautada no consumo desenfreado. Para sustentar esse consumo exacerbado, foi necessária igual exacerbação de produção, e, por sua vez, para produzir mais, foi necessário explorar mais recursos naturais, transformando a natureza.

Acontece que essa transformação da natureza correu a altos custos. Os recursos naturais começam a apresentar sinais de desestabilidade, e se intensificam os problemas ambientais. Um olhar ingênuo sobre esses problemas aponta para a falsa ideia de que os mesmos são de natureza estritamente ecológica, no entanto, uma análise mais crítica apontará para a problemática real, que se refere a uma crise do modelo de sociedade vigente, também chamada de crise socioambiental, que, como bem definiu Vasconcelos,

[...] em termos mais simples e objetivos, como sendo um processo histórico, cumulativo e crescente no interior do modelo civilizatório em voga, caracterizado por sucessivos desequilíbrios, desordens, antagonismos, incorreções e desvios generalizados, ocorridos nas várias áreas com profundos, significativos e complexos desdobramentos que se tornaram relevantes, evidentes, incompatíveis, ameaçadores e imprevisíveis, a partir, sobretudo, das últimas décadas, sem que tenha havido, até o momento, qualquer perspectiva de superação prática e consensual, ou ao menos, de minimização de seus efeitos deletérios a toda humanidade e ao planeta Terra como um todo. (VASCONCELOS, 2011, p.17)

Logo, percebe-se que a crise chamada ambiental, vivenciada pela população mundial, na verdade, se trata de uma crise que se origina de um modelo de desenvolvimento insustentável do ponto de vista socioambiental, tanto pelos problemas ambientais (ecológicos) quanto pelos problemas sociais decorrentes e paralelos.

Diante deste cenário, cabe questionar se o papel da escola seria continuar reproduzindo o padrão de consumo e de sociedade estabelecido ou seria buscar por novos padrões de desenvolvimento que permitissem a existência de uma sociedade mais equitativa.

A resposta do modelo capitalista e, por consequência da escola como aparelho ideológico, vai ao sentido de desviar os olhares do verdadeiro problema e direcionar para os problemas estritamente ecológicos. A visão utilitarista da natureza preencheu e ainda preenche os discursos ambientais de diversas escolas. O homem, nessa concepção, é ser isolado do meio ambiente. O discurso ambiental se apresenta dissociado de qualquer outra esfera da sociedade.

A tentativa de estabelecer um diálogo mais crítico sobre os problemas socioambientais na escola tem sido tolhida pela função reprodutora da ideologia capitalista.

Nesse contexto, a Educação Ambiental, que tem estado mais presente nas escolas, chegando a ser considerada prática universalizada (VEIGA; AMORIM; BLANCO, 2005), tem ficado restrita a uma abordagem naturalista, ecológica, ingênua e distante da discussão histórica e política necessária (RIBEIRO; RAMOS, 1999; LOZANO; MUCCI, 2005; VIANA; OLIVEIRA, 2006; MACHADO, 2008). Essa visão ingênua sobre a EA retira os holofotes da real problemática do sistema de produção capitalista e tenta transferir todos os problemas ambientais para os indivíduos, fazendo-os acreditar 
que jogar papel nas ruas e usar sacolas plásticas são os verdadeiros problemas, quando, na verdade, eles são de outra ordem. Não que os cidadãos não sejam, também, responsáveis, mas querer igualar a responsabilidade desses à do setor econômico configura-se como subterfúgio característico da ideologia capitalista de manutenção do status quo social, de produção, consumo e intensificação de lucros.

A EA não pode ser tratada como fatalismo ou como um conjunto de comportamentos reproduzidos impositivamente, ela deve ser instrumento de dúvida, priorizando a crítica para atingir a transformação. Nos dizeres de Gadotti, deve-se questionar se

[...] educar é reproduzir ou transformar, repetir servilmente aquilo que foi, optar pela segurança do conformismo, pela fidelidade à tradição ou, ao contrário, fazer frente à ordem estabelecida e correr o risco da aventura; querer que o passado configure todo o futuro ou partir dele para construir outra coisa. (GADOTTI, 2010, p. 43).

Logo, as práticas estritamente ecológicas, de reconhecimento dos recursos naturais, de sensibilização e comportamentalistas não podem ser confundidas com a EA crítica, pois falta, a essas atividades, o caráter questionador, de discutir as intrincadas relações políticas e históricas que se relacionam com os problemas socioambientais.

\subsection{O papel da educação ambiental crítica diante da problemática socioambiental}

Antes de adentrar na discussão sobre a importância da EA crítica diante da problemática socioambiental, é importante esclarecer que, apesar de ser um campo de pesquisa que está longe de apresentar consenso, podem-se destacar duas grandes correntes de entendimento sobre a EA, quais sejam: a conservadora ou conservacionista, de um lado, e a crítica emancipatória, de outro. A primeira se atrela a uma vertente que considera que os problemas ambientais são de natureza ecológica apenas, e que a superação dos desastres e catástrofes ambientais, bem como a diminuição da supressão dos recursos naturais, aconteceria com a participação individual de cada cidadão mudando seus hábitos, onde a transformação individual levaria a uma transformação da sociedade. Já na segunda vertente, considera-se que os problemas socioambientais sejam decorrentes de um modelo de civilização, seriam problemas estruturais, e, logo, a superação dos mesmos somente pode ocorrer com a consciência crítica desse modelo, buscando, de forma coletiva, social, a superação do paradigma político-econômico vivido, almejando mais equidade social e ambiental.

Para mudar o cenário de insustentabilidade em que vive a humanidade e promover mudanças ambientais e sociais, a EA crítica é instrumento importante, pois auxilia a cultivar, no coletivo, a consciência da necessidade de participação social e política para a promoção da mudança.

Karl Marx, apesar de não apresentar obra específica sobre a temática ambiental, deixou, como legado, muitas contribuições para se pensar uma prática socioambiental crítica. O projeto político-econômico capitalista, de mascarar o verdadeiro problema subsidiando a EA conservacionista, deve ser combatido e substituído por um projeto de EA crítica.

A sustentabilidade material e social exige muito mais do que criar formas menos predatórias de produzir, seja por medidas racionalizadas, através de processos de reciclagem [...] seja pelo consumo verde e ambientalização dos consumidores. Todas estas medidas nada mais são, de um lado, do que formas que o capital encontra para escamotear os problemas que vão da produção ao consumo e, de outro, para prolongar as condições de sua sobrevivência. (TREIN, 2007, p. 119)

É preciso que a EA adquira um caráter crítico, no sentido de proporcionar uma visão histórica e ampla dos acontecimentos e projetos idealizados para a sociedade, a fim de revelar a raiz dos problemas para, a partir daí, poder se pensar e estabelecer meios adequados para, de fato, combater e tratar os problemas socioambientais e não mais continuar maquiando-os.

De forma complementar, Paulo Freire, citado por Misiaszek e Torres (2008), argumentou que as pedagogias críticas, estendendo-se à EA crítica, são necessárias na identificação da ideologia dominante e no esclarecimento da possibilidade de superação da injusta realidade.

A dialética de Marx foi um dos importantes legados deixados pelo autor que permite um olhar mais crítico para os problemas socioambientais que afligem a sociedade. Pressupõe a existência e o 
movimento de contrários, considera a dinâmica de existência dos fenômenos e possibilita a revelação das contradições, escamoteando as aparências dos problemas.

A dialética pressupõe, também, a relação entre homem e natureza. Alicerça a compreensão crítica da problemática socioambiental e o abandono do pensamento alienado, valorizando a práxis ambiental, que exige a articulação entre prática e teoria, uma vez que prática sem teoria se transforma em ativismo, e teoria sem prática se revela em puro discurso (FREIRE, 1987).

Compreendendo a EA como parte da superestrutura e, ainda, como sendo dinâmica, não há como pensá-la de forma desvinculada dos fenômenos sociais, políticos e econômicos que acontecem na sociedade.

Ainda, como fazendo parte de um modelo dinâmico de contrários, uma análise mais atenta sobre o que se tem chamado de EA (práticas de reconhecimento, preservação de recursos naturais, sem vinculação com fatores econômicos políticos e sociais, conforme mencionado em citações anteriores de estudos realizados em escolas) permite questionar a qual ideologia essas práticas tem estado atreladas e, ainda, a quem essas práticas interessam.

A EA crítica, envolta pela perspectiva marxista, é capaz de denunciar a apropriação que os setores econômicos hegemônicos tem feito da expressão desenvolvimento sustentável, que foi reduzida a comportamentos ecológicos, afastando os olhares da crise da civilização que se encontra por trás da sociedade (TOZONI-REIS, 2007). A práxis crítica de estudo dos problemas socioambientais pressupõe o constante movimento de questionamento das relações existentes entre sociedade e educação e pressupõe, também, a valorização de análises interpretativas críticas da realidade, afastando a ingenuidade da reprodução de padrões hegemônicos inculcados na sociedade através da prática ingênua da EA.

Por fim, a EA crítica deve auxiliar o processo de formação de cidadãos conscientes, que superem a ideologia e a hegemonia que ainda dominam a sociedade, buscando novos paradigmas de sociedade, mais igualitária, justa e socioambientalmente equilibrada, implicada na incorporação das dimensões social, ética, política e econômica (NOVICKI, 2010) no processo de ensino e, sobretudo, na abordagem da EA nos ambientes escolares.

\section{CONSIDERAÇÕES FINAIS}

Por tudo exposto considera-se que os problemas socioambientais vivenciados pela sociedade são resultantes do modelo de desenvolvimento capitalista, pautado no consumo e na reprodução alienada dos padrões necessários á manutenção do status quo da sociedade. Um dos meios utilizados para a reprodução desse modelo é a escola, como aparelho ideológico do Estado, que amplifica a ideologia capitalista e mascara a raiz dos problemas socioambientais.

Nesse sentido, as práticas escolares de Educação Ambiental conservacionistas, difundidas nas instituições formais de ensino, têm se mostrado incapazes de gerar transformações efetivas, pois desviam os olhares da problemática socioambiental, reduzindo-a a questões ecológicas, de resolução comportamentalista e individual.

Por fim, a Educação Ambiental crítica é alternativa para tentar superar a reprodução alienada dos padrões dominantes, priorizando uma formação questionadora, crítica e consciente sobre os problemas socioambientais, bem como a superação dos mesmos.

\section{AGRADECIMENTOS}

À Coordenação de Aperfeiçoamento de Pessoal de Nível Superior (Capes).

\section{REFERÊNCIAS}

ALTHUSSER, Louis. Ideologia e aparelhos ideológicos do Estado. 3 ed. Lisboa: Presença, 1980.

BODGAN, Robert C; BIKLEN, Sari Knopp. Investigação qualitativa em educação. Portugal: Porto Editora, 1994. 
DIAS, Genebaldo Freire. Ecopercepção: um resumo didático dos desafios socioambientais. São Paulo: Gaia, 2004.

FREIRE, Paulo. Pedagogia do oprimido. 17ª ed. Rio de Janeiro: Paz e Terra, 1987.

GADOTTI, Moacir. Pedagogia da práxis. 5ª̣ ed. São Paulo: Cortez: Instituto Paulo Freire, 2010.

GONZALEZ GAUDIANO, Edgar; KATRA, Lyle Figueroa de. Valores e educação ambiental: aproximações teóricas em um campo em contínua construção. Educação e Realidade, Porto Alegre, v. 34, n. 03, p. 41-65, set/dez 2009. Disponível em: < http://www.seer.ufrgs.br/index.php/educacaoerealidade/article/ view/9081/6707>. Acesso em 07 jan. 2015.

LAYARGUES, Philippe Pomier. A natureza da ideologia e a ideologia da natureza: elementos para uma sociologia da educação ambiental. 2003. 105 f. Tese (Doutorado) - Instituto de Filosofia e Ciências Humanas, Universidade Estadual de Campinas. Campinas, SP. Disponível em: $<$ http://www.bibliotecadigital.unicamp. $\underline{\mathrm{br} / \mathrm{document} / \text { ?code }=\mathrm{vtls} 000293110}>$. Acesso em 22 set. 2014.

LIMA, Gustavo Ferreira da Costa. Crise Ambiental, educação e cidadania: os desafios da sustentabilidade emancipatória. In: LOUREIRO, Carlos Frederico Bernardo; LAYRARGUES, Philippe Pomier; CASTRO, Ronaldo Souza de. (orgs.). Educação ambiental: repensando o espaço de cidadania. São Paulo: Cortez, 2002. p. 109-141.

LOZANO, Marcia da Silva; MUCCI, José Luiz Negrão. A Educação Ambiental em uma escola da rede estadual de ensino no município de Santo André: análise situacional. Revista eletrônica do Mestrado em Educação Ambiental. V. 14, p.132-151, Jan./jun. 2005. Disponível em <http://www.seer.furg.br/remea/article/ view/2890>. Acesso em 01 jan. 2015.

MACHADO, Júlia Teixeira. Um estudo diagnóstico da Educação Ambiental nas escolas do ensino fundamental do município de Piracicaba/SP. 2008. 195f. Dissertação (Mestrado). Universidade de São Paulo, São Paulo. Disponível em < http://www.teses.usp.br/teses/disponiveis/91/91131/tde-07032008-160949/pt-br. php>. Acesso em 06 jan. 2015.

MARCONI, M. de A.; LAKATOS, E. M. Técnicas de pesquisa. 5 ed. São Paulo: Atlas, 2002.

MARX, Karl. O Capital: Crítica da Economia Política. São Paulo: Nova Cultural, 1996. (Os Pensadores, Livro 1, Tomo 2).

MARX, Karl; ENGELS, Friedrich. Manifesto comunista. 5ª Reimpressão. São Paulo: Boitempo, 2007.

MISIASZEK, Greg William; TORRES, Carlos Alberto. Ideologia. In: STRECK, Danilo R.; REDIN, Euclides; ZITKOSKI, Jaime José (orgs.). Dicionário Paulo Freire. Belo Horizonte: Autêntica Editora, 2008. p.222-224.

NOVICKI, Victor. Práxis: problematizando consciência e participação na educação ambiental brasileira. In: LOUREIRO, Carlos Frederico B. et al. A questão ambiental no pensamento crítico: natureza, trabalho e educação. Rio de Janeiro: Quartet, 2007, p.135-175.

PEDROSA, José Geraldo. O capital e a natureza no pensamento crítico. In: LOUREIRO, Carlos Frederico B. et al. A questão ambiental no pensamento crítico: natureza, trabalho e educação. Rio de Janeiro: Quartet, 2007, p.69-112.

RIBEIRO, Marizélia Rodrigues Costa; RAMOS, Fernando Antônio Guimarães. Educação ambiental no cotidiano escolar: estudo de caso etnográfico. Cadernos de Pesquisa, São Luís. v. 10, n.2, p. 9-21, jul./dez. 1999. Disponível em: <http://www.pppg.ufma.br/cadernosdepesquisa/?content=page\&group=38\&selected=31>. Acesso em 07 jan. 2015. 
TOZONI-REIS, Marília Freitas de Campos. Contribuições para uma pedagogia crítica na educação ambiental: reflexões teóricas. In: LOUREIRO, Carlos Frederico B. et al. A questão ambiental no pensamento crítico: natureza, trabalho e educação. Rio de Janeiro: Quartet, 2007, p.177-221.

TREIN, Eunice. A contribuição do pensamento marxista à educação ambiental. In: LOUREIRO, Carlos Frederico B. et al. A questão ambiental no pensamento crítico: natureza, trabalho e educação. Rio de Janeiro: Quartet, 2007, p.113-134

VASCONCELOS, Vicente Simão de. A formação do sujeito ecológico por meio da Educação Ambiental crítica a partir de concepções pedagógicas Paulo Freireanas. 2011. 107f. Dissertação (Mestrado). Pontifícia Universidade Católica de Minas Gerais, Belo Horizonte.

VEIGA, Alinne; AMORIM, Érica; BLANCO, Maurício. Um Retrato da Presença da Educação Ambiental no Ensino Fundamental Brasileiro: o percurso de um processo acelerado de expansão. Brasília: Instituto Nacional de Estudos e Pesquisas Educacionais Anísio Teixeira, 2005.

VIANA, Pedrina Alves Moreira Oliveira; OLIVEIRA, José Everaldo. A inclusão do tema meio ambiente nos currículos escolares. Revista eletrônica do Mestrado Educação Ambiental, v.16, p.1-17, jan./jun. 2006. Disponível em: < http://www.seer.furg.br/remea/article/view/2777/1566 >. Acesso em 07 jan. 2015. 